\title{
Quantitative evaluation of soil ion content using an imaginary part model of soil dielectric
}

\section{constant}

\author{
Wei Hu${ }^{1}$, Lei Zhang ${ }^{2} \oplus$, Binglin Chen ${ }^{1}$, Zhiguo Zhou ${ }^{1 *} \oplus$
}

\author{
${ }^{1}$ Nanjing Agricultural University/College of Agriculture, 1 \\ Weigang Road - 210095 - Nanjing - China. \\ ${ }^{2}$ South China Agricultural University/College of Agriculture \\ - Dept. of Crop Science, 483 Wushan Road - 510642 - \\ Guangzhou - China. \\ *Corresponding author < giscott@njau.edu.cn>
}

Edited by: Paulo Cesar Sentelhas

Received December 23, 2017

Accepted March 11, 2018

\begin{abstract}
An imaginary part model of soil dielectric constant for predicting the soil salinity status was developed based on a series of relations between dielectric imaginary part and soil bulk conductivity, soil bulk conductivity and soil solution electrical conductivity, and soil solution electrical conductivity and ion contents in soil using pot trials with different soil salinity levels in the 2008 growing season. This model was calibrated and tested with data from the 2009 growing season. The results showed that the inverted values of the total concentration of salt (Sc), $\mathrm{Cl}^{-}$, and $\mathrm{Ca}^{2+}$ at low frequencies (P-band of microwave observations) from the imaginary part model fitted well with the observed values, since root mean square errors (RMSEs) were $0.34 \mathrm{~g} \mathrm{~kg}^{-1}, 0.09 \mathrm{~g} \mathrm{~kg}^{-1}$ and $0.13 \mathrm{~g} \mathrm{~kg}^{-1}$, respectively, but the inversion effect of $\mathrm{Na}^{+}$was relatively poor. Moreover, the $\mathrm{Sc}, \mathrm{Cl}^{-}$, and $\mathrm{Na}^{+}$could be well inverted at high frequencies (C-band of microwave observations), since RMSEs were minor, with values of $0.25 \mathrm{~g} \mathrm{~kg}^{-1}, 0.02 \mathrm{~g} \mathrm{~kg}^{-1}$, and $0.15 \mathrm{~g} \mathrm{~kg}^{-1}$, respectively. The close fit between the observed and inverted values indicated that the present models could be used to estimate soil ion content quickly and reliably under different saline conditions, which, when suitable measures are taken, can be used to reduce the effects of soil salinity on crop growth.
\end{abstract}

Keywords: microwave sensing, prediction, soil salinity

\section{Introduction}

At the turn of the century salt-affected land worldwide was more than 77 million hectares and approximately 43 million hectares of land was suffering from secondary salinization $(F A O, 2000)$. Salinity stress has become one of the major soil problems in agricultural production, and many agriculture experts have turned their attention to the improving saline soil (Richards, 1954). Usually, soil salinization has been detected using traditional chemical methods which have proved to be exceptionally labor intensive and time wasting (Shrestha and Farshad, 2008). This has been expected to lead to the rapid development of inexpensive tools for assessing soil salinity (Metternicht and Zinck, 2003). Several researchers have attempted to identify soil salinity status using visible and near-infrared waves (Peñuelas et al., 1997; Wiegand et al., 1994). However, given that the amount of soil salt detected using remote sensing is higher than the actual value (Sreenivas et al., 1995), there is a need to evaluate sensors that use electrical properties such as microwave radars.

Compared with optical sensing, microwave sensing offers expressive advantages for detecting soil conditions. Several studies have utilized C-band, P-band and L-band to detect the characterization of soil (Sreenivas et al., 1995; Taylor and Mah, 1996; Xiong and Shao, 2006). Several mixing models of dielectric constant have been conducted on the soil-water systems, such as the fourcomponent mixing model and the Dobson semi-empirical model (Wang and Schmugge, 1980; Dobson et al., 1985; Jackson and O'Neill, 1987; Peplinski et al., 1995). However, the models are not applicable to all particular kinds of soil. When soils have a high salt content, the conductance of soil will be high, and the imaginary part of dielectric constant in this case will also be higher, indicating that the imaginary part of dielectric constant is more dependent on the salt ion in soil media (Sreenivas et al., 1995; Bell et al., 2001). Xiong and Shao (2006) also reported that the influences of salinity on dielectric constant should be specifically considered. In recent years, the rapid development of microwave remote sensing enables us to measure the imaginary part of dielectric constant speedily and easily. If we could establish the relation between the imaginary part of dielectric constant and soil ion contents, measuring the soil ion concentrations would be a very easy task, which will reduce labor intensity and save time. Consequently, this study tried to construct an imaginary part model of a dielectric constant to monitor the soil ion contents.

\section{Materials and Methods}

\section{Experimental design}

A pots experiment was conducted in a half open greenhouse construction to control precipitation in 2008 and 2009 in Nanjing, China $\left(32^{\circ} 02^{\prime} \mathrm{N}, 118^{\circ} 50^{\prime} \mathrm{E}, 26\right.$ $\mathrm{m})$. Cotton cultivars CCRI-44 and Sumian 12 were used. Seeds were planted in a nursery bed on 25 Apr in 2008 and 2009. At the three true leaves stage, seedlings were transplanted into plastic pots. Pot size was $50 \mathrm{~cm}$ high and $33 \mathrm{~cm}$ wide and the pots were filled with air dried soil (30 kg per pot) after passing through a $2 \mathrm{~mm}$ sieve. The soil was collected from the topsoil layer $(0-30 \mathrm{~cm})$ in the experimental field and the physical and chemical properties of the soil are presented in Table 1. 
Table 1 - Nutrients contents, physical and chemical properties of the basic soil in 2008 and 2009.

\begin{tabular}{|c|c|c|c|c|c|c|c|c|c|c|c|c|c|c|}
\hline \multirow{2}{*}{ Year } & \multicolumn{3}{|c|}{ Nutrient content (mg kg-1) } & \multicolumn{11}{|c|}{ Physical and chemical properties } \\
\hline & $\mathrm{TNC}^{\mathrm{a}}$ & $\mathrm{APC}^{\mathrm{b}}$ & $\mathrm{AKC}^{\mathrm{C}}$ & $\mathrm{pH}$ & $\mathrm{BD}^{\mathrm{d}}$ & FWC & $E C^{f}$ & $\mathrm{HCO}_{3}^{-}$ & $\mathrm{SO}_{4}^{2-}$ & $\mathrm{Cl}^{-}$ & $\mathrm{Ca}^{2+}$ & $\mathrm{Mg}^{2+}$ & $\mathrm{Na}^{+}$ & $\mathrm{K}^{+}$ \\
\hline & & & & & $\mathrm{g} \mathrm{cm}^{-3}$ & $\%$ & ds $\mathrm{m}^{-1}$ & & & & $\mathrm{~mol} \mathrm{~kg}$ & & & \\
\hline 2008 & $1.11 \times 10^{3}$ & 27.83 & 132.73 & 6.62 & 1.23 & 28.55 & 1.22 & 0.21 & 4.72 & 0.53 & 1.96 & 0.37 & 5.33 & 0.29 \\
\hline 2009 & $0.92 \times 10^{3}$ & 31.94 & 120.55 & 7.80 & 1.27 & 28.02 & 1.25 & 0.19 & 4.52 & 0.53 & 2.06 & 0.40 & 5.66 & 0.33 \\
\hline
\end{tabular}

${ }^{\mathrm{a}}$ Total N content; ${ }^{\mathrm{b}} \mathrm{Available} \mathrm{P}$ content; ' $\mathrm{Available} \mathrm{K}$ content; ${ }^{\mathrm{d} B u l k}$ density; ${ }^{\mathrm{e}}$ Field water capacity; ${ }^{\mathrm{F}}$ Electrical conductivity.

Seven types of salt $\left(\mathrm{NaHCO}_{3}: \mathrm{Na}_{2} \mathrm{CO}_{3}: \mathrm{NaCl}\right.$ : $\mathrm{MgSO}_{4}: \mathrm{CaCl}_{2}: \mathrm{MgCl}_{2}: \mathrm{Na}_{2} \mathrm{SO}_{4}=1: 1: 1: 1: 1: 1: 1$ | were mixed into the sieved soils before starting the experiment (Zhang et al., 2012). Five levels of salinity were designated as $0 \mathrm{mg} \mathrm{kg}^{-1}$ (CK, control), $35 \mathrm{mg} \mathrm{kg}^{-1}$ (S1), $60 \mathrm{mg} \mathrm{kg}^{-1}$ (S2), $85 \mathrm{mg} \mathrm{kg}^{-1}$ (S3) and $100 \mathrm{mg} \mathrm{kg}^{-1}$ (S4), which corresponded to the soil solution conductivity (soil: water $=1: 5$ ) of $1.25,5.80,9.61,13.23$, and 14.65 $\mathrm{dS} \mathrm{m}^{-1}$, respectively, and were similar to the local coastal saline soil (Zhang et al., 2012). The layout of the pots was random. Each treatment had 20 pots considered as 20 replications. The dielectric constant and soil ion content were recorded on 1 June (seedling stage), 3 July (budding stage), 15 Aug (boll-setting stage) and $10 \mathrm{Sept}$ (boll-opening stage) in both years.

\section{Laboratory analysis}

For each treatment, four replicate soil cores (diameter $=3 \mathrm{~cm}$, depth $=20 \mathrm{~cm}$ ) were selected and mixed. The instantaneous soil water content was measured using the gravimetric method after the soil samples were dried at $105^{\circ} \mathrm{C}$ (Zhang et al., 2012). The soil was filled in an aluminum cup to a known volume. All soil samples required distilled water to be added to treat the soil water content as the original measurement. After $24 \mathrm{~h}$ an open-ended coaxial probe and a network analyzer were used to measure the imaginary part of dielectric properties at $0.5 \mathrm{GHz}$ (P-band) and $5.25 \mathrm{GHz}$ (C-band). To perform these measurements, the probe tip was inserted in the material and was kept in close contact with the material, and the ancillary software of the network analyzer extracted the imaginary part from the reflected signal. Additionally, EC, $\mathrm{pH}$, and salt compositions in the soil-water (1:5) extract were assayed by the standard methods (Liu et al., 2008; Zhang et al., 2017).

\section{Statistical analysis}

The data collected in 2008 were used to develop the imaginary part model of the dielectric constant. The model was tested using independent data from 2009. Root mean square error (RMSE) values were used to evaluate the goodness of fit between predicted values and observed values in the 1:1 plotting of the two sets of values. The RMSE is calculated using the following equation:

$$
R M S E=\sqrt{\frac{1}{n} \sum_{j=1}^{n}\left(Y_{j}-X_{j}\right)^{2}}
$$

where $Y_{j}$ are the predicted values, $X_{j}$ the observed values, and $\mathrm{n}$ the sample number.

All statistical calculations were performed using the SPSS program (version 16.0).

\section{Results and Discussion}

\section{Effects of soil salinity on the ion content in soil}

The results in Table 2 showed that as the growth stage progressed, the concentration of $\mathrm{Na}^{+}, \mathrm{K}^{+}, \mathrm{Ca}^{2+}$, $\mathrm{Mg}^{2+}, \mathrm{HCO}_{3}^{-}, \mathrm{Cl}^{-}, \mathrm{SO}_{4}^{2-}$ decreased, although the decreasing amplitude became larger as the soil salinity increased, differing from the former study in the field (Van Hoorn et al., 1997). The concentration of $\mathrm{Na}^{+}, \mathrm{K}^{+}, \mathrm{Ca}^{2+}$, $\mathrm{Mg}^{2+}, \mathrm{HCO}_{3}^{-}, \mathrm{Cl}^{-}$, and $\mathrm{SO}_{4}{ }^{2-}$ increased with elevated soil salinity at every growth stage of cotton, suggesting that soil salinity had significant effects on ion content in soil.

\section{Model development}

Xiong and Shao (2006) built an imaginary part model for a mixture of water and soil to which with sodium chloride based on a series of relations was added. According to the guiding ideology of establishing the model in an experiment, the imaginary part model in our study can utilize the method of relationship derivation to connect the imaginary part of dielectric constant to the soil ion content. Previous studies have reported the relation between dielectric imaginary part and soil bulk conductivity (Xiong and Shao, 2006), and that between soil bulk conductivity and soil solution electrical conductivity (Shainberg et al., 1980). In the current experiment, we needed to establish the relation between soil solution electrical conductivity and soil ion contents. Then, based on the series of relationships, we could use the easily measured imaginary part of dielectric constant to predict the soil salinity status. The detailed derivation process was described in the following subsections.

\section{The relation between the imaginary part of the soil dielectric constant and soil bulk electrical conductivity}

Soil is a complex of air, water, and soil particles. The imaginary part of the soil dielectric permittivity is usually expressed in terms of dielectric losses, which are influenced by soil electrical conductivity and the soil itself (Corwin and Lesch, 2003). Previous research has shown that electrical conductivity loss plays a very important role in determining the imaginary part of dielectric constant $\left(\varepsilon^{\prime \prime}\right)$ at both low and high frequency, the relaxation 
Table 2 - Changes of ion contents in cotton pots under different soil salinity rates in 2008.

\begin{tabular}{|c|c|c|c|c|c|c|c|c|}
\hline \multirow{2}{*}{ Growth stage } & \multirow{2}{*}{$\begin{array}{l}\text { Salinity rate } \\
\left(\mathrm{dS} \mathrm{m} \mathrm{m}^{-1}\right)\end{array}$} & \multicolumn{7}{|c|}{ Ion content (g kg-1) } \\
\hline & & $\mathrm{HCO}_{3}^{-}$ & $\mathrm{Cl}^{-}$ & $\mathrm{SO}_{4}^{2-}$ & $\mathrm{Ca}^{2+}$ & $\mathrm{Mg}^{2+}$ & $\mathrm{K}^{+}$ & $\mathrm{Na}^{+}$ \\
\hline \multirow{5}{*}{ Seedling stage } & 1.25 & $0.0091 \mathrm{e}$ & $0.0111 \mathrm{e}$ & $0.0193 \mathrm{e}$ & $0.1700 \mathrm{e}$ & $0.1098 \mathrm{e}$ & $0.0069 \mathrm{e}$ & $0.1250 \mathrm{e}$ \\
\hline & 5.80 & $0.0104 \mathrm{~d}$ & $0.0554 \mathrm{~d}$ & $0.0362 \mathrm{~d}$ & $0.4000 \mathrm{~d}$ & $0.1891 \mathrm{~d}$ & $0.0137 \mathrm{~d}$ & $0.3625 \mathrm{~d}$ \\
\hline & 9.61 & $0.0131 \mathrm{c}$ & $0.1365 c$ & $0.0610 \mathrm{c}$ & $0.4720 \mathrm{c}$ & $0.2097 c$ & $0.0200 \mathrm{c}$ & $0.7125 \mathrm{c}$ \\
\hline & 13.23 & $0.0143 b$ & $0.1418 b$ & $0.0696 \mathrm{~b}$ & $0.5500 \mathrm{~b}$ & $0.2745 b$ & $0.0227 \mathrm{~b}$ & $0.8515 b$ \\
\hline & 14.65 & $0.0151 \mathrm{a}$ & $0.1737 a$ & $0.0720 \mathrm{a}$ & $0.5950 \mathrm{a}$ & $0.3172 \mathrm{a}$ & $0.0288 \mathrm{a}$ & $1.0875 \mathrm{a}$ \\
\hline \multirow{5}{*}{ Budding stage } & 1.25 & $0.0086 \mathrm{e}$ & $0.0113 \mathrm{e}$ & $0.0176 \mathrm{e}$ & $0.1410 \mathrm{e}$ & $0.0732 \mathrm{~d}$ & $0.0068 \mathrm{e}$ & $0.0800 \mathrm{e}$ \\
\hline & 5.80 & $0.0095 d$ & $0.0456 \mathrm{~d}$ & $0.0286 \mathrm{~d}$ & $0.3815 d$ & $0.1542 \mathrm{c}$ & $0.0113 d$ & $0.2722 d$ \\
\hline & 9.61 & $0.0116 \mathrm{c}$ & $0.0886 \mathrm{c}$ & $0.0534 \mathrm{c}$ & $0.4800 \mathrm{c}$ & $0.1543 c$ & $0.0187 \mathrm{c}$ & $0.6375 c$ \\
\hline & 13.23 & $0.0125 b$ & $0.1108 b$ & $0.0581 \mathrm{~b}$ & $0.5161 \mathrm{~b}$ & $0.2562 b$ & $0.0207 \mathrm{~b}$ & $0.8125 b$ \\
\hline & 14.65 & $0.0137 a$ & $0.1586 \mathrm{a}$ & $0.0672 \mathrm{a}$ & $0.5616 \mathrm{a}$ & $0.2928 \mathrm{a}$ & $0.0275 a$ & $1.0250 \mathrm{a}$ \\
\hline \multirow{5}{*}{ Flowering and boll-forming stage } & 1.25 & $0.0056 \mathrm{e}$ & $0.0119 d$ & $0.0168 c$ & $0.1200 \mathrm{e}$ & $0.0632 \mathrm{e}$ & $0.0068 \mathrm{e}$ & $0.0625 \mathrm{e}$ \\
\hline & 5.80 & $0.0076 \mathrm{~d}$ & $0.0326 c$ & $0.0345 b$ & $0.3466 \mathrm{~d}$ & $0.1325 d$ & $0.0103 d$ & $0.2253 d$ \\
\hline & 9.61 & $0.0104 \mathrm{c}$ & $0.0905 b$ & $0.0432 b$ & $0.4200 \mathrm{c}$ & $0.1769 c$ & $0.0150 \mathrm{c}$ & $0.5875 c$ \\
\hline & 13.23 & $0.0110 b$ & $0.0959 \mathrm{~b}$ & $0.0480 a b$ & $0.4594 \mathrm{~b}$ & $0.2075 b$ & $0.0188 b$ & $0.6875 b$ \\
\hline & 14.65 & $0.0119 a$ & $0.1489 a$ & $0.0600 \mathrm{a}$ & $0.4900 \mathrm{a}$ & $0.2135 a$ & $0.0237 \mathrm{a}$ & $0.8875 a$ \\
\hline \multirow{5}{*}{ Boll-opening stage } & 1.25 & $0.0043 \mathrm{e}$ & $0.0115 \mathrm{e}$ & $0.0144 \mathrm{e}$ & $0.1406 \mathrm{~d}$ & $0.0405 d$ & $0.0065 d$ & $0.0250 \mathrm{e}$ \\
\hline & 5.80 & $0.0070 d$ & $0.0316 \mathrm{~d}$ & $0.0240 \mathrm{~d}$ & $0.3066 \mathrm{c}$ & $0.0793 c$ & $0.0068 d$ & $0.2125 d$ \\
\hline & 9.61 & $0.0092 \mathrm{c}$ & $0.0642 \mathrm{c}$ & $0.0331 \mathrm{c}$ & $0.3900 \mathrm{~b}$ & $0.1281 \mathrm{~b}$ & $0.0113 c$ & $0.4375 c$ \\
\hline & 13.23 & $0.0103 b$ & $0.0717 \mathrm{~b}$ & $0.0336 \mathrm{~b}$ & $0.3905 \mathrm{~b}$ & $0.1342 b$ & $0.0137 \mathrm{~b}$ & $0.6750 \mathrm{~b}$ \\
\hline & 14.65 & $0.0110 \mathrm{a}$ & $0.1294 \mathrm{a}$ & $0.0480 \mathrm{a}$ & $0.4200 \mathrm{a}$ & $0.1575 \mathrm{a}$ & $0.0225 \mathrm{a}$ & $0.7750 \mathrm{a}$ \\
\hline
\end{tabular}

For each growth stage, different letters in the same column indicate a significant difference at 0.05 level.

loss becomes a more important factor (Zhang et al., 2012). Xiong and Shao (2006) have proved that dielectric losses of deionized water could be ignored at low frequency, but should be considered at high frequency. Moreover, a linear regression relationship was detected between $\varepsilon$ " and soil bulk conductivity $\left(\sigma_{a}\right)$ at both low and high frequency in their experiment. Combining this knowledge with the relationship between $\varepsilon^{\prime \prime}$ and $\sigma_{a^{\prime}}$ the equation of $\varepsilon^{\prime \prime}$ was generated with a relatively simple form and a high degree of accuracy for both low and high frequencies.

At low frequency (P- band), a linear regression analysis was conducted between $\varepsilon^{\prime \prime}$ and $\sigma_{a}$.

$\varepsilon^{\prime \prime}=2.1577 \sigma_{a}-2.7142\left(n=40, \mathrm{R}^{2}=0.86\right) \quad f<3 G h z$

where $f$ is the frequency. At high frequency (C-band), the dielectric loss caused by water cannot be ignored (Zhang et al., 2012). Thus, considering the water dielectric loss, $\varepsilon^{\prime \prime}$ calculated as:

$\varepsilon^{\prime \prime}=0.446 M_{v} \varepsilon^{\prime \prime}{ }_{w}+0.527 \sigma_{a}-4.995\left(n=40, \mathrm{R}^{2}=0.84\right)$ $f \geq 3 \mathrm{Ghz}$

where $\varepsilon_{w}$ " is the imaginary part of dielectric constant of deionized water, $\sigma_{a}$ a constant at constant temperature, and $M_{v}$ the soil volume water content.

\section{The relation between soil bulk electrical conductivity and electrical conductivity of soil solution}

The $\sigma_{a}$ can serve as an indicator of soil salinity. Accordingly, $\sigma_{a}$ is represented by the summation of two terms (Shainberg et al., 1980): $\sigma_{a}=c \sigma_{w}+\sigma$

where $c$ is a geometry factor, $\sigma_{w}$ the electrical conductivities of the 1:5 soil-water extract and $\sigma_{s}$ the matrix surface. At a high solution concentration, $\sigma_{s}$ approaches an ultimate value, and equation (4) becomes a linear function of $\sigma_{w}$ (Mualem and Friedman, 1991). However, as the soil water content increases, $\sigma_{a}$ is further affected by the soil volumetric water content. Accounting for this effect, a new relationship for $\sigma_{a}$ and $\sigma_{w}$ was developed as follows:

$\sigma_{a}=3.341 \sigma_{w} M_{v}+0.810 \quad\left(\mathrm{n}=40, \mathrm{R}^{2}=0.88\right)$

The relation between electrical conductivity of soil solution and soil ion content

Soil salinity is quantified based on the total concentrations of salts, which could be indicated by the electrical conductivity of soil-water solution ( $\left.\mathrm{dS} \mathrm{m} \mathrm{m}^{-1}\right)$ (Corwin and Lesch, 2005). However, the chemical composition also affects soil electrical conductivity. McNeal et al. (1970) established a relationship between electrical conductivity of soil-water solution and molar concentrations of salts. Griffin and Jurinak (1973) also detected a linear regression relationship between soil electrical conductivity and the ion contents of soils to which only $\mathrm{NaCl}$ was added. However, when soil salinity is indicated by $\sigma_{w}$ many factors, such as total salinity and soil salt composition will affect the measurement of $\sigma_{w}$ of saline soil. For example, Zhang et al., (2017) found that the $\sigma_{w}$ was higher in the water-soil system with high salt content relative to the water-soil system with low salt 
content. Correlation analyses were conducted between the dependent variable $\sigma_{w}$ and independent variables including total salt content of soils, ion concentration, sodium adsorption ratio, and sodium dianion ratio (SDR) (Table 3).

Related factors such as total concentration of salt $(\mathrm{Sc}), \mathrm{Cl}^{-}, \mathrm{Ca}^{2+}$ and $\mathrm{Na}^{+}$had significant correlations $\left(\mathrm{R}^{2}>\right.$ $0.90)$ with $\sigma_{w}$ of saline soil, indicating $\mathrm{Sc}_{c} \mathrm{Cl}^{-}, \mathrm{Ca}^{2+}$, and $\mathrm{Na}^{+}$were important factors when determining $\sigma_{w}$. Regression functions between $\sigma_{w}$ and $\mathrm{Sc}, \mathrm{Cl}^{-}, \mathrm{Ca}^{2+}$ as well as $\mathrm{Na}^{+}$contents were established as follows:

$$
\begin{aligned}
& \sigma_{w}=4.222 S_{c}+0.474 \quad\left(n=40, \mathrm{R}^{2}=0.92\right) \\
& \sigma_{w}=6.028 \mathrm{Ca}^{2+}+2.806 S_{c}+0.040\left(\mathrm{n}=40, \mathrm{R}^{2}=0.94\right) \quad 7 \\
& \sigma_{w}=8.613 \mathrm{Cl}^{-}+5.796 \mathrm{Ca}^{2+}+2.150 \mathrm{~S}_{c}+0.223 \\
& \left(\mathrm{n}=40, \mathrm{R}^{2}=0.94\right) \\
& \sigma_{w}=2.028 \mathrm{Cl}^{-}+0.122 \mathrm{Ca}^{2+}-6.392 \mathrm{Na}^{+}+7.488 S_{c}-0.201 \\
& \left(n=40, \mathrm{R}^{2}=0.95\right)
\end{aligned}
$$

where $S_{c}$ is the total concentration of salt, $\mathrm{Cl}^{-}$the concentration of anion $\mathrm{Cl}^{-}$in $\mathrm{g} \mathrm{kg}^{-1}, \mathrm{Ca}^{2+}$ the concentration of cation $\mathrm{Ca}^{2+}$ in $\mathrm{g} \mathrm{kg}^{-1}$, and $\mathrm{Na}^{+}$the concentration of cation $\mathrm{Na}^{+}$in $\mathrm{g} \mathrm{kg}^{-1}$.

\section{Inversion of soil ion content based on the imaginary part model of dielectric constant}

The data in 2009 were used for verifying the developed model. In Figure 1, a comparison of the inversed and observed values of $\mathrm{Sc}, \mathrm{Cl}^{-}, \mathrm{Ca}^{2+}$ and $\mathrm{Na}^{+}$, was presented at different salinity levels at low frequency (P-band). A very strong agreement between the inversed and observed data was noted for $\mathrm{Sc}_{\mathrm{C}} \mathrm{Cl}^{-}$ and $\mathrm{Ca}^{2+}\left(\mathrm{R}^{2}\right.$ were 0.94,0.69, 0.80, and RMSE were $0.34 \mathrm{~g} \mathrm{~kg}^{-1}, 0.09 \mathrm{~g} \mathrm{~kg}^{-1}, 0.13 \mathrm{~g} \mathrm{~kg}^{-1}$ for $\mathrm{Sc}, \mathrm{Cl}^{-}, \mathrm{Ca}^{2+}$, respectively) (Table 4). As regards the $\mathrm{Na}^{+}$, a large error occurring at low frequency (P-band) $\left(\mathrm{R}^{2}\right.$ and $\mathrm{RMSE}$ were 0.0015 and $0.21 \mathrm{~g} \mathrm{~kg}^{-1}$, respectively), indicated that the $\mathrm{Na}^{+}$content in soil cannot be predicted well at low frequency using the model. The results in Figure 2 show a comparison of the inversed values and the observed values of $\mathrm{Sc}, \mathrm{Cl}^{-}, \mathrm{Ca}^{2+}$, and $\mathrm{Na}^{+}$at high frequency (C-band). The good results were observed for Sc, $\mathrm{Cl}^{-}$and $\mathrm{Na}^{+}\left(\mathrm{R}^{2}\right.$ were $0.87,0.84,0.82$ and RMSE were $0.25 \mathrm{~g} \mathrm{~kg}^{-1}, 0.02 \mathrm{~g} \mathrm{~kg}^{-1}, 0.15 \mathrm{~g} \mathrm{~kg}^{-1}$ for $\mathrm{Sc}, \mathrm{Cl}^{-}$, $\mathrm{Na}^{+}$, respectively), although the inversed $\mathrm{Ca}^{2+}$ values were lower than the observed values where $\mathrm{Ca}^{2+}$ content was high at high frequency (C-band) $\left(\mathrm{R}^{2}\right.$ and RMSE were 0.81 and $0.21 \mathrm{~g} \mathrm{~kg}^{-1}$, respectively). These results showed the potential of this inversion model to accurately invert $\mathrm{Sc}, \mathrm{Cl}^{-}, \mathrm{Ca}^{2+}$, and $\mathrm{Na}^{+}$in saline soil at both low and high frequencies. Compared to previous models constructed under signal $\mathrm{NaCl}$ salinity to estimate the soil electrical conductivity (Leao et al., 2010), our simulation could be used to further invert the ion content based on the imaginary part of soil dielectric
Table 3 - Correlation coefficients between chemical properties of soil extract and EC, and between any two chemical properties of soil extract.

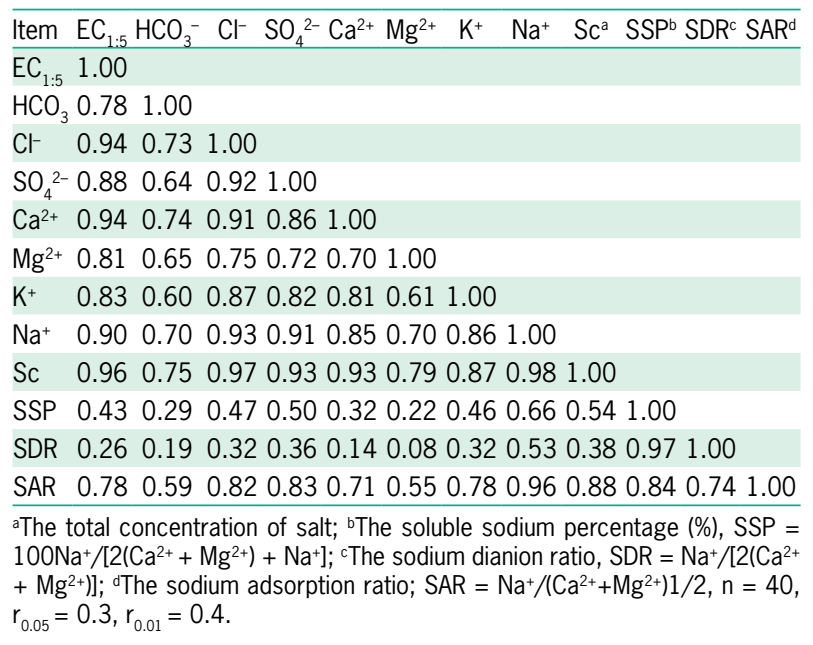

Table 4 - Testing results of the imaginary part of dielectric constant model at low frequency (P-band) and at high frequency (C-band).

\begin{tabular}{lclll}
\hline Frequency & Ion content & Regression equations & \multicolumn{1}{c}{$\mathrm{R}^{2}$} & RMSE \\
\hline \multirow{4}{*}{ P-band } & $\mathrm{Sc}^{\mathrm{a}}$ & $\mathrm{y}=0.8821 \mathrm{x}+0.1669$ & 0.69 & 0.34 \\
& $\mathrm{Cl}^{-}$ & $\mathrm{y}=1.1014 \mathrm{x}-0.0099$ & 0.80 & 0.09 \\
& $\mathrm{Na}^{+}$ & $\mathrm{y}=-0.07 \mathrm{x}+0.5589$ & 0.0015 & 0.21 \\
& $\mathrm{Ca}^{2+}$ & $\mathrm{y}=1.8238 \mathrm{x}-0.1966$ & 0.82 & 0.13 \\
\hline \multirow{4}{*}{ C-band } & $\mathrm{Sc}$ & $\mathrm{y}=0.9383 \mathrm{x}-0.0298$ & 0.87 & 0.25 \\
& $\mathrm{Cl}^{-}$ & $\mathrm{y}=0.9274 \mathrm{x}-0.0043$ & 0.81 & 0.02 \\
& $\mathrm{Na}^{+}$ & $\mathrm{y}=0.9095 \mathrm{x}-0.0106$ & 0.84 & 0.15 \\
& $\mathrm{Ca}^{2+}$ & $\mathrm{y}=0.8475 \mathrm{x}-0.0051$ & 0.94 & 0.21 \\
\hline The total concentration of salt. & & &
\end{tabular}

constant. Xiong and Shao (2006) have also constructed an imaginary part model of soil dielectric constant to invert the total salt contents. However, their experiment was conducted in $\mathrm{NaCl}$ salinity only, but our experiment involved the inversion of a variety of salt ions. Wei et al. (2017) tried to obtain a new imaginary part model of dielectric constant for the salt soil by improving the Dobson semi-empirical model used in a water-soil system, but the modified imaginary part model was easily affected by the water content in soil, resulting in low accuracy in the model. However, the model developed in our experiment is highly reliable for predicting total salt and multiple ion concentrations, which was conducive to providing information for proper soil management.

Our experiment was carried out using pots. The practicability of the model for the saline field under wider moisture conditions can be further tested. Furthermore, other factors, such as soil texture, can influence the soil dielectric constant (Hallikainen et al., 1985; Sreenivas et al., 1995). Thus, further adjustment of the model should include further consideration of the soil texture under more variable environmental conditions. 

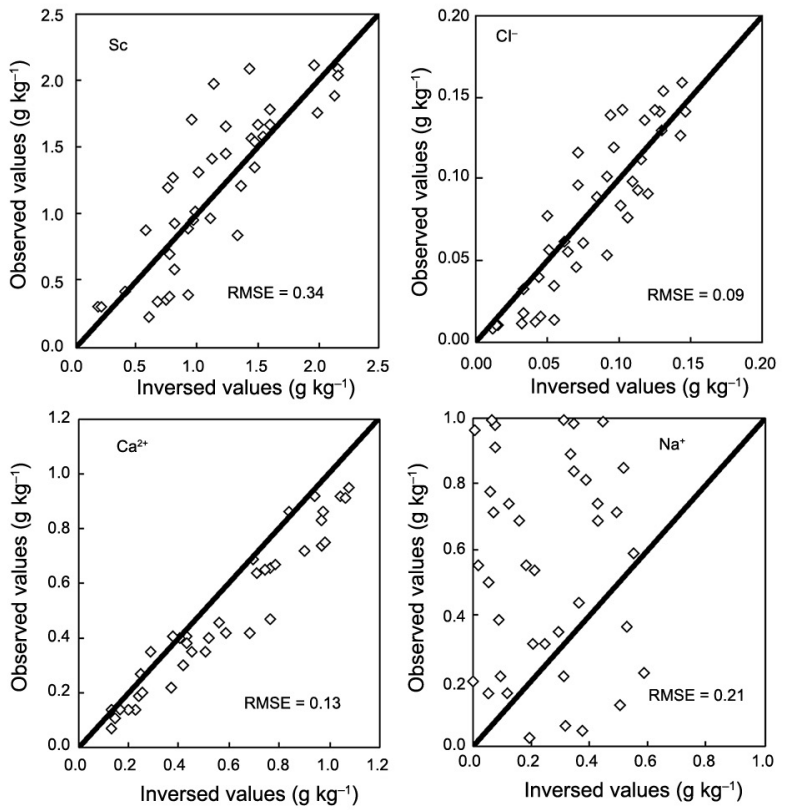

Figure $\mathbf{l}$ - Comparison between the inversed and the observed values of total salt (Sc), $\mathrm{Cl}^{-}, \mathrm{Ca}^{2+}$ and $\mathrm{Na}^{+}$contents based on the imaginary part of dielectric constant model at low frequency ( $\mathrm{n}$ $=40$ ).
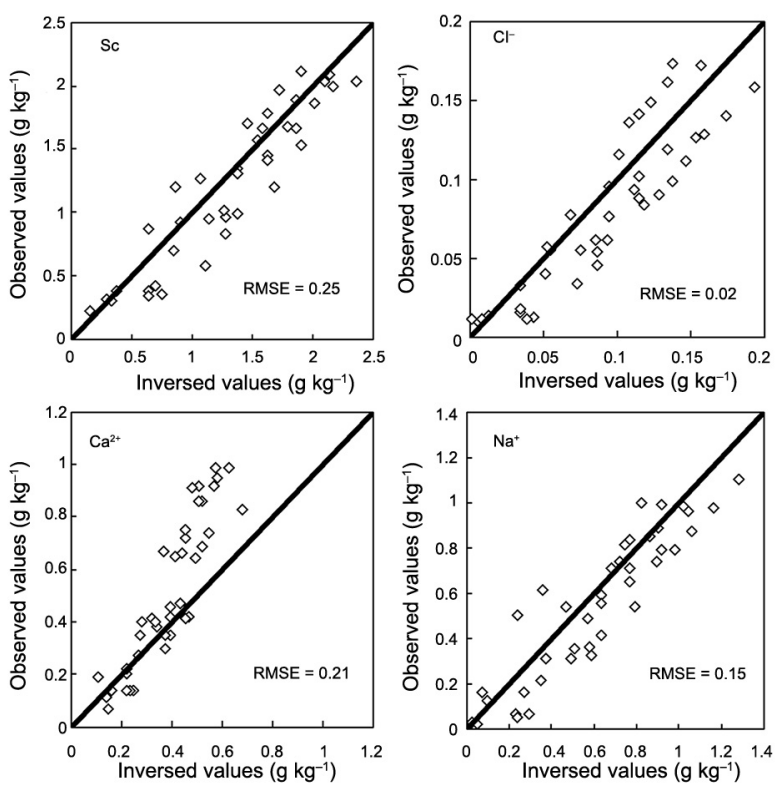

Figure 2 - Comparison between the inversed and the observed values of total salt (Sc), $\mathrm{Cl}^{-}, \mathrm{Ca}^{2+}$ and $\mathrm{Na}^{+}$contents based on the imaginary part of dielectric constant model at high frequency ( $\mathrm{n}$ $=40$ ).

This study is the first attempt to characterize a group of soils with a wide range of soil ion content, and develop a new dielectric constant model relating to $\varepsilon^{\prime \prime}$ and soil ion content. This model inverts the soil ion content easily, which could provide references for producers to take appropriate measures to reduce the effects of soil salinity on crop growth.

\section{Conclusions}

In the present study, an imaginary part model of soil dielectric constant was constructed by studying the relations between the imaginary part of the dielectric constant and soil bulk conductivity, soil bulk conductivity and soil solution conductivity, and, finally, soil solution conductivity and the soil ion contents. The comparison between inverted values and observed values indicated that the soil ion contents $\left(\mathrm{Sc}_{,} \mathrm{Cl}^{-}, \mathrm{Ca}^{2+}\right.$ and $\mathrm{Na}^{+}$) at different soil salinity levels could be well inverted using the imaginary part model of the dielectric constant. The present experiment confirmed the potential of microwave sensing in monitoring ion contents in soil. In the future, we shall also need to conduct more trials in the field with a wider range of soil textures and salt components.

\section{Acknowledgments}

The research was supported by the National Natural Science Foundation of China (31671623), Jiangsu Special Fund for Water-scientific Research (2013038, 2012020, 2011073), China Agriculture Research System (CARS-18-14) and the Jiangsu Collaborative Innovation Center for Modern Crop Production (JCIC-MCP).

\section{Authors' Contributions}

Conceptualization: Zhou, Z.G. Data acquisition: $\mathrm{Hu}$, W.; Zhang, L.; Chen, B.L. Data analysis: Hu, W.; Zhang, L. Design of Methodology: Hu, W.; Zhang, L.; Chen, B.L.; Zhou, Z.G. Writing and editing: $\mathrm{Hu}$, W.; Zhang, L.; Zhou, Z.G.

\section{References}

Bell, D.; Menges, C.; Ahmad, W.; Van Zyl, J.J. 2001. The application of dielectric retrieval algorithms for mapping soil salinity in a tropical coastal environment using airborne polarimetric SAR. Remote Sensing of Environment 75: 375-384.

Corwin, D.; Lesch, S. 2003. Application of soil electrical conductivity to precision agriculture. Agronomy Journal 95: 455-471.

Corwin, D.; Lesch, S. 2005. Apparent soil electrical conductivity measurements in agriculture. Computers and Electronics in Agriculture 46: 11-43.

Dobson, M.C.; Ulaby, F.T.; Hallikai, M.T.; El-rayes, M.A. 1985. Microwave dielectric behavior of wet soil. II. Dielectric mixing models. IEEE Transactions on Geoscience and Remote Sensing 1: $35-46$.

Food and Agriculture Organization [FAO]. 2000. Extent and causes of salt-affected soils in participating countries. Available at: http://www.fao.org/ag/agl/agll/spush/topic2.htm [Accessed Nov 10, 2000]

Griffin, B.; Jurinak, J. 1973. Estimation of activity coefficients from the electrical conductivity of natural aquatic systems and soil extracts. Soil Science 116: 26-30. 
Hallikainen, M.T.; Ulaby, F.T.; Dobson, M.C.; El-Rayes, M.A.; Wu, L.K. 1985. Microwave dielectric behavior of wet soil. I. Empirical models and experimental observations. IEEE Transactions on Geoscience and Remote Sensing 1: 25-34.

Jackson, T.J.; O'Neill, P.E. 1987. Salinity effects on the microwave emission of soils. IEEE Transactions on Geoscience and Remote Sensing 2: 214-220.

Leao, T.P.; Perfect, E.; Tyner, J.S. 2010. New semi-empirical formulae for predicting soil solution conductivity from dielectric properties at $50 \mathrm{MHz}$. Journal of Hydrology 393: 321-330.

Liu, R.X.; Zhou, Z.G.; Guo, W.Q.; Chen, B.L.; Oosterhuis, D.M. 2008. Effects of $\mathrm{N}$ fertilization on root development and activity of water-stressed cotton (Gossypium hirsutum L.) plants. Agricultural Water Management 95: 1261-1270.

McNeal, B.L.; Oster, J.D.; Hatcher, J.T. 1970. Calculation of electrical conductivity from solution composition data as an aid to in-situ estimation of soil salinity. Soil Science 110: 405414.

Metternicht, G.I.; Zinck, J.A. 2003. Remote sensing of soil salinity: potentials and constraints. Remote Sensing and Environment 85: 1-20.

Mualem, Y.; Friedman, S.P. 1991. Theoretical prediction of electrical conductivity in saturated and unsaturated soil. Water Resource 27: 2771-2777.

Peñuelas, J.; Isla, R.; Filella, I.; Araus, J.L. 1997. Visible and nearinfrared reflectance assessment of salinity effects on barley. Crop Science 37: 198-202.

Peplinski, N.R.; Ulaby, F.T.; Dobson, M.C. 1995. Dielectric properties of soils in the $0.3-1.3 \mathrm{Ghz}$ range. IEEE Transactions on Geoscience and Remote Sensing 33: 803-807.

Richards, L.A. 1954. Diagnosis and improvement of saline and alkaline soils. Soil Science 5: 432.

Shainberg, T.; Rhoades, J.D.; Prather, R.J. 1980. Effects of exchangeable sodium percentage, cation exchange capacity and soil solution concentration on soil electrical conductivity. Soil Science Society of America Journal 44: 469-473.
Shrestha, D.P.; Farshad, A. 2008. Mapping salinity hazard: an integrated application of remote sensing and modellingbased techniques. p. 257-270. In: Metternicht, G.I.; Zinck, J.A., eds. Remote sensing of soil salinization: impact on land management. CRC Press, Boca Raton, FL, USA.

Sreenivas, K.; Venkataratnam, L.; Rao, P.V.N. 1995. Dielectric properties of salt-affected soils. International Journal of Remote Sensing 16: 641-649.

Taylor, G.R.; Mah, A.H. 1996. Characterization of saline soil using Airborne Radar Imagery. Remote Sensing of Environment 57: 127-142.

Van Hoorn, J.W.; Katerji, N.; Hamdy, A. 1997. Long-term salinity development in a lysimeter experiment. Agricultural Water Management 34: 47-55.

Wang, J.R.; Schmugge, T.J. 1980. An empirical model for the complex dielectric permittivity of soils as a function of water content. IEEE Transactions on Geoscience and Remote Sensing 4: 288-295.

Wei, L.; Wang, W.Z.; Wu, Y.R.; Ma, C.F. 2017. Comparative analysis of soil water and salt dielectric model. Remote Sensing Technology and Application 32: 1022-1030.

Wiegand, C.L.; Rhoades, J.D.; Escobar, D.E.; Everitt, J.H. 1994. Photographic and videographic observations for determining and mapping the resource of cotton to soil-salinity. Remote Sensing of Environment 3: 212-223.

Xiong, W.C.; Shao, Y. 2006. Model for imaginary part of dielectric constant of $\mathrm{NaCl}$ soil. Journal of Remote Sensing 10: 279-286.

Zhang, H.; Li, D.; Zhou, Z.; Zahoor, R.; Chen, B.; Meng, Y. 2017. Soil water and salt affect cotton (Gossypium hirsutum L.) photosynthesis, yield and fiber quality in coastal saline soil. Agricultural Water Management 187: 112-121.

Zhang, L.; Tang, M.; Zhang, G.; Zhou, Z. 2012. Monitoring and simulation of soil electrical conductivity based on the hyperspectral parameters of cotton (Gossypium hirsutum) functional leaves. Journal of Applied Ecology 23: 710-716. 